\title{
O Plano Geral de Melhoramentos do Funchal (1915), de Miguel Ventura Terra
}

\author{
Gerbert Verheij \\ gerbertverheii@vfemail.net
}

Centro e Investigação e de Estudos em Belas-Artes da Faculdade de Belas-artes da Universidade de Lisboa (CIEBA), Portugal

Para citação: VERHEIJ, Gerbert - O Plano Geral de Melhoramentos do Funchal (1915), de Miguel Ventura Terra. Estudo Prévio 14. Lisboa: CEACT/UAL - Centro de Estudos de Arquitetura, Cidade e Território da Universidade Autónoma de Lisboa, 2018. ISSN: 2182-4339 [Disponível em: www.estudoprevio.net]. DOI: https://doi.org/10.26619/2182-4339/14.1

Recensão recebida a 15 de Abril de 2018 e aceite para publicação a 17 de Junho de 2018.

Creative Commons, licença CC BY-4.0: https://creativecommons.org/licenses/by/4.0/

A presente recensão traça o estado de arte sobre o Plano Geral de Melhoramentos do Funchal, elaborado pelo arquiteto Miguel Ventura Terra entre 1913 e 1915. Avança ainda argumentas pela sua importância dentro da história do urbanismo português do século XX e identifica perspetivas de investigação futura.

$\mathrm{O}$ arquiteto Miguel Ventura Terra (1866-1919) foi um dos mais importantes arquitetos portugueses do início do século XX. De origens humildes, estudou arquitetura no Porto e depois, como pensionista do Estado, em Paris, no atelier de Victor Laloux. De regresso a Portugal, em 1894, tornou-se um dos mais relevantes e prestigiados arquitetos do seu tempo. Deixou uma vasta obra, desempenhou várias funções públicas e teve um papel destacado na promoção da profissão do arquiteto em Portugal. [1] Em 1908 foi eleito vereador da Câmara Municipal de Lisboa. Durante o mandato de pouco mais que quatro anos se dedicou intensamente aos problemas urbanísticos. Trabalhou num novo Plano Geral de Melhoramentos, em vários ambiciosos projetos de intervenção urbana e na atualização da atuação municipal na área do urbanismo e da arquitetura, publicitando amplamente a sua proposta de uma Lisboa moderna e cosmopolita. [2]

Certamente com a sua atuação em Lisboa em mente, a vereação do Funchal, desejosa de adaptar a cidade ao peso crescente do turismo na economia local, endereçou em 1912 um convite ao arquiteto para elaborar um Plano Geral de Melhoramentos. Semanas após o fim do seu mandato lisboeta, Ventura Terra já está na Madeira para conhecer a cidade, os seus problemas e potencialidades. Em setembro de 1913 enviou desde Lisboa os primeiros elementos deste plano, seguido de um anteprojeto em 1914 e o projeto final em 
1915, então aprovado. Algumas avenidas foram construídas. Logo a seguir a Primeira Guerra Mundial interrompeu os trabalhos. No entanto, o Plano de Ventura Terra mantémse uma referência incontornável para as diferentes propostas urbanísticas que the seguiram, e é por isso uma peça essencial para entender o desenvolvimento urbano da cidade.

Apesar desta importância, o Plano foi basicamente esquecido até há pouco mais que uma década. Consta do catálogo da exposição retrospetiva de Ventura Terra (RIBEIRA, 2006), incluindo alguns elementos fornecidos pelo historiador madeirense Rui Carita, que, contudo, não permitiam um entendimento pleno do Plano. Foi a dissertação de mestrado de Teresa Vasconcelos, orientado pelo mesmo Rui Carita e depois publicada em livro (VASCONCELOS, 2008), que fez a primeira abordagem mais completa das ambições do plano e do seu contexto histórico, recorrendo também a uma Memória Descritiva e Justificativa, entretanto localizada. Seguiram-se duas dissertações de mestrado (PERDIGÃO, 2009; MAIA, 2010) que aprofundaram aspetos morfológicos e confirmaram a importância do Plano de Ventura Terra para propostas urbanísticas posteriores. [3] Uma exposição organizada pela Delegação da Madeira da Ordem dos Arquitetos por ocasião do centenário da aprovação do Plano mostrou-o em todo o seu esplendor, acompanhada de um bom catálogo (100 ANOS, 2015).

Os estudos mencionados analisam o Plano Geral de Melhoramentos do Funchal essencialmente no plano local, dentro do contexto da evolução urbana da cidade. Não avaliam, nem pretendem avaliar, a sua importância dentro da história do urbanismo em Portugal ou mesmo na obra de Ventura Terra. Em publicações sobre estes temas o Plano é, no melhor dos casos, mencionados superficialmente, provavelmente por falta de conhecimento direto da documentação, menos acessível de uma perspetiva continental.[4] A exposição "Ventura Terra, Arquiteto: Do útil e do bello," que a Câmara Municipal de Lisboa organizou em 2017,[5] foi - como notou na altura Vasco Rosa (2017) - uma oportunidade perdida para um frutífero confronto entre as propostas para Lisboa e Funchal. Para vê-lo a escala real era preciso ir a Cascais, onde uma reprodução do Plano integrava discretamente a exposição "Miguel Ventura Terra, Vida e Obra, Casas de Cascais," na Fundação D. Luís. [6]

Face a este diagnóstico acrescento alguns apontamentos para argumentar pela importância do plano quer na obra de Ventura Terra, quer na história do urbanismo em Portugal, esperando contribuir para novas perspetivas de investigação.

Enquanto à obra do arquiteto, o Plano do Funchal parte em boa medida das mesmas premissas que as que Ventura Terra propôs para Lisboa. Admitindo as diferenças de escala, há tipologias comuns, nomeadamente o passeio marginal com equipamentos dedicados ao lazer e o espaço de receção para visitantes vindos por mar, a atenção constante à ligação da cidade com o rio e ao aproveitamento das suas paisagens, os valores cosmopolitas e burgueses e, em geral, a preocupação com a "beleza" e "conforto" urbanos, sempre contra o pano de fundo da circulação. No entanto, em Lisboa, e ao contrário do Funchal, nunca chegou a apresentar o Plano Geral de Melhoramentos proposto logo no início do mandato, e só restam referências avulsas.[7]

Acresce que no decurso do seu trabalho enquanto vereador Ventura Terra contactou com a nascente cultura urbanística internacional. Estamos a falar de um período crucial na 
formação das disciplinas urbanísticas em Europa e nos Estados Unidos: conceitos-base, legislação, instituições e as próprias palavras urbanisme, town e city planning aparecem na década antes da Primeira Guerra Mundial. Ventura Terra tinha acesso a esta cultura. Participante assíduo dos Congressos Internacionais dos Arquitetos, é provável que aí tenha contactado com ideias então debatidas. [8]

O Plano de Funchal, tendo chegado até nós completo, é assim uma peça por excelência para aferir até que ponto Ventura Terra tenha assimilados os preceitos dessa nascente cultura urbanística, que nesta altura já ia bem além do modelo haussmanniano. Enquanto a isso, é possível realçar numa primeira abordagem:

a perspetiva integral da cidade, pensando a reforma da cidade existente e a expansão urbana em conjunto;

as metodologias de trabalho atualizadas;

as ambições de ordenação urbana, nomeadamente através de uma forma rudimentar de zoneamento dos bairros (ver os Bairros ... e ... do Plano);

as preocupações em reforçar o controlo público sobre a arquitetura da iniciativa privada;

e a atenção ao desenho do espaço público e à integração de equipamentos públicos, em contraste com as ações de loteamento em que consistia o grosso do urbanismo oitocentista.

Mantém, é claro, o papel estrutural das comunicações viárias e a preferência pela soluçãoimagem da avenida, já bem experimentada em Portugal.

Na perspetiva mais alargada da história do urbanismo em Portugal, o Plano de Funchal é um caso muito interessante e por explorar. Não são muitos os Planos Gerais de Melhoramentos aprovados que se conhecem. Sem dúvida o mais conhecido é o de Lisboa, elaborado sob direção de Ressano Garcia e aprovado em 1904. Ora, o Plano de Lisboa é essencialmente uma ratificação formal dos projetos de expansão implementados nas décadas anteriores (as Avenidas Novas), a que são acrescentados um grande parque e algumas vias de ligação entre o centro e os limites da cidade. Deixa intocada a cidade existente e ignora as áreas de expansão ao longo do rio, onde se vinham instalando indústrias e populações menos abastadas. O próprio Ressano Garcia admite as insuficiências do plano na Memória Descritiva e Justificativa, desculpando-se com a falta de fundos e meios. Na prática, era um plano de expansão urbana limitada. Ventura Terra foi muito crítico do trabalho desenvolvido sob direção de Ressano Garcia, e é por isso de todo pertinente o confronto entre o Plano de $1904 \mathrm{com}$ as propostas do arquiteto para Lisboa e Funchal.

Outro confronto relevante é com as propostas praticamente contemporâneas de Barry Parker para o Porto. Este sócio de Raymond Unwin, coautor dos projetos das cidadesjardins de Letchworth e Hampstead, foi contratado para redesenhar a Avenida dos Aliados, projeto depois ampliado para todo o centro urbano. Pode ser outro caminho fértil para sondar melhor a cultura urbanística portuguesa neste período complexo de transição entre - urbanismo oitocentista representado por Ressano Garcia e o urbanismo institucionalizado pelo Estado Novo na década de 1930, e perspetivas como estas são essenciais para uma visão mais completa dos primeiros passos do urbanismo nacional na sua complexidade e especificidade históricas. 


\section{Notas}

1. As principais referências para o arquiteto e a sua obra são os dois catálogos editados por A. I. Ribeiro (2006) e Xardoné, Costa e Rufino (2009).

2. Esta era a primeira vereação totalmente republicana a gerir o município, antecipando a implantação da República dois anos mais tarde. A vereação resignou coletivamente em janeiro de 1913, alegando cansaço e desilusão com o novo regime. Para contexto, ver Câmara Municipal de Lisboa (2010). A obra urbanística de Ventura Terra em Lisboa é largamente discutida em Verheij (2017). Das propostas de Ventura Terra quase nada se realizou na altura, mas é curioso como muito do que propôs ecoa nos projetos urbanos implementados durante a última década.

3. O essencial de Perdigão foi resumido numa comunicação (PERDIGÃO, VIRTUDES, 2010); a mesma retomou o tema na sua tese de doutoramento (2013), sem introduzir novidades. Já em 2007 outra dissertação de mestrado analisara o Plano do Funchal, sem acesso às fontes entretanto publicadas por Vasconcelos. Esta dissertação foi integralmente publicada como artigo em 2010, já desatualizada (BETTENCOURT, 2010).

4. Não é, por exemplo, mencionado numa obra de referência como a de M. S. Lobo (1995). A digitalização do plano pela Delegação da Madeira da Ordem dos Arquitetos promete alargar o acesso ao Plano. Esperamos que também se segue a publicação integral da Memória Descritiva e Justificativa, preservada na Direção Regional dos Assuntos Culturais em Funchal, de grande interesse dada a escassez de produção escrita sobre urbanismo nestas primeiras décadas do século XX.

5. Ver http://arquivomunicipal.cm-lisboa.pt/pt/eventos/ventura-terra-arquiteto/ [consult. 15 junho 2018].

6.

http://fundacaodomluis.pt/index.php?option=com_content\&view=article\&id=433:miguelventura-terra-cascais-portugal-fundacao-d-luis\&catid=72:destaques [consult. 15 junho 2018].

7. Para este e o seguinte parágrafo remeto novamente para a minha tese de doutoramento (VERHEIJ, 2017).

8. Enquanto representante da Câmara Municipal de Lisboa esteve inscrito na Town Planning Conference de 1910 (Londres), momento-chave na formação da town planning britânica. Acabou por não assistir, provavelmente porque a conferência teve lugar pouco depois da Revolução Republicana de outubro, em que Ventura Terra esteve ativamente envolvido.

\section{Bibliografia}

100 Anos do Plano Ventura Terra: Funchal, a cidade do automóvel. Funchal: Ordem dos Arquitetos, Secção Regional do Sul, Delegação da Madeira, 2015.

BETTENCOURT, Luísa Catarina Freitas Andrade - A Morfologia Urbana da Cidade do Funchal e os seus espaços públicos estruturantes. Malha Urbana - Revista Lusófona de 
PT | L01 | EP14 | w2018

Urbanismo [Em linha]. Vol. 10 (2010), p. 1-283 [Consult. 15 junho 2018]. Disponível na internet: <http://recil.grupolusofona.pt/handle/10437/2274>.

CÂMARA MUNICIPAL DE LISBOA, ed. - Colóquio Nacional Lisboa e a República: Centenário da Vereação Republicana de Lisboa 1908-2008. Lisboa: Câmara Municipal de Lisboa, 2010.

GAMA, José Gil Correia - Arquitetura e turismo na cidade do Funchal no século XX. [Em linha]. Coimbra: Universidade de Coimbra, 2011. [Consult. 15 junho 2018]. Disponível na internet: <http://hdl.handle.net/10316/15823>. Dissertação de mestrado.

LOBO, Margarida Souza - Planos de urbanização: A época de Duarte Pacheco. 2. ${ }^{a}$ ed. Porto: Faculdade de Arquitetura da Universidade do Porto, 1995.

PERDIGÂO, Cristina Sofia - Formação do centro urbano do Funchal: Contributo das transformações urbanísticas. [Em linha]. Covilhã: Universidade da Beira Interior, 2009.
[Consult.
15 junho
2018].
Disponível
na
internet:

<http://ubibliorum.ubi.pt/handle/10400.6/3336>. Dissertação de mestrado.

- O turismo na Madeira. Dinâmicas e ordenamento do território do turismo em territórios insulares. [Em linha]. Lisboa: Universidade de Lisboa, 2013. [Consult. 15 junho 2018]. Disponível na internet: <https://www.repository.utl.pt/handle/10400.5/14518>. Tese de doutoramento.

PERDIGÂO, Cristina Sofia; VIRTUDES, Ana Lídia - Transformações urbanísticas modernas no Funchal: Contributos para a cidade turística. [Em linha]. In 16ํㅡㄹ Congresso da Associação Portuguesa de Desenvolvimento Regional. Regiões de Charneira, Canais de Fronteira e Nós. Atas / Proceedings. Funchal: APDR, 2010. p. 242-64. [Consult. 15 junho 2018]. Disponível na na

internet: $<$ http://apdr.pt/data/documents/Atas_16_Congresso_APDR.pdf>.

RIBEIRO, Ana Isabel, ed. - Miguel Ventura Terra: A arquitetura enquanto projeto de vida. Esposende: Câmara Municipal de Esposende, 2006.

ROSA, Vasco - O arquiteto vereador: 150 anos de Ventura Terra. [Em linha]. Observador. Lisboa. 25 julho 2017. [Consult. 15 junho 2018]. Disponível na internet: <https://observador.pt/2017/07/25/o-arquiteto-vereador150-anos-de-ventura-terra/>.

VERHEIJ, Gerbert - The Aesthetic of Lisbon: Writing and practices during the early 20th Century [Em linha]. Barcelona: Universitat de Barcelona, 2017. [Consult. 15 junho 2018]. Disponível na internet: <http://diposit.ub.edu/dspace/handle/2445/113642>. Tese de doutoramento.

XARDONÉ, Tereza; COSTA, Rui; RUFINO, Maria de Lurdes, eds. - Arquiteto / Architect Ventura Terra, 1866-1919. Lisboa: Assembleia da República, 2009.

VASCONCELOS, Teresa - O Plano Ventura Terra e a Modernizaçao do Funchal (Primeira Metade do Século XX). Funchal: Empresa Municipal "Funchal 500 Anos," 2008. 